\title{
A Retrospective and Prospective Follow-up Study of Psychological Distress in the Danwon High School Survivors of the Sewol Ferry Disaster
}

\author{
Eun Ji Kim ${ }^{1 *}$, Hee Sun $\mathrm{Nam}^{1 *}$, Hak Beom Kim² , Unsun Chung ${ }^{3}$, So Hee Lee ${ }^{4 凶}$, and Jeong-Ho Chae ${ }^{5 凶}$ \\ ${ }^{1}$ Mind Health Center, Ansan, Republic of Korea \\ ${ }^{2}$ Children Welfare Center, Incheon, Republic of Korea \\ ${ }^{3}$ Department of Psychiatry, Kyungpook National University Children's Hospital, Daegu, Republic of Korea \\ ${ }^{4}$ Department of Psychiatry, National Medical Center, Seoul, Republic of Korea \\ ${ }^{5}$ Department of Psychiatry, Seoul St. Mary's Hospital, The Catholic University of Korea College of Medicine, Seoul, Republic of Korea
}

Objective We monitored a group of students from Danwon High School who survived the Sewol ferry disaster for 27 months to examine the course of their psychological symptoms.

Methods We performed a chart review at the Danwon High School Mental Health Center at the following time points (T): 9 months (T1), 12 months (T2), and 15 months (T3) after the disaster. Additionally, we performed a follow-up review at 27 months (T4). Subjects completed the 'State' section of the State-Trait Anxiety Inventory for Children, the Center for Epidemiological Studies-Depression assessment, the Child Report of Post-traumatic Symptoms, and the Inventory of Complicated Grief. Data from the 32 subjects who completed all four assessments were used in the statistical analyses.

Results Scores of psychological variables tended to increase until T2 and then slowly decreased until T4. The severity of anxiety and complicated grief symptoms changed significantly over time, but the severity of depression and posttraumatic stress symptoms did not.

Conclusion We found that the symptoms of anxiety and complicated grief reported by Sewol ferry survivors from Danwon High School were exacerbated at the first anniversary of the disaster, but these symptoms subsided after the students graduated from high school.

Psychiatry Investig 2018;15(3):261-265

Key Words Danwon, Sewol ferry disaster, Anxiety, Complicated grief, Anniversary.

\section{INTRODUCTION}

On April 16, 2014, the Sewol ferry sank off the southwest coast of South Korea. Only 181 of the 476 passengers survived. Among the survivors was a group of students from the same

\footnotetext{
Received: May 23, 2017 Accepted: June 25, 2017

$\triangle$ Correspondence: So Hee Lee, MD, PhD

Department of Psychiatry, National Medical Center, 245 Eulji-ro, Jung-gu, Seoul 04564, Republic of Korea

Tel: +82-2-2260-7311, Fax: +82-2-2268-5028, E-mail: psyhee@hanmail.net

$\triangle$ Correspondence: Jeong-Ho Chae, MD, PhD

Department of Psychiatry, Seoul St. Mary's Hospital, The Catholic University of Korea College of Medicine, 222 Banpo-daero, Seocho-gu, Seoul 06591, Republic of Korea

Tel: +82-2-2258-6083, Fax: +82-2-594-3870, E-mail: alberto@catholic.ac.kr

*These authors contributed equally to this work.

(a) This is an Open Access article distributed under the terms of the Creative Commons Attribution Non-Commercial License (http://creativecommons.org/licenses/bync/4.0) which permits unrestricted non-commercial use, distribution, and reproduction in any medium, provided the original work is properly cited.
}

high school who had been on a school trip and were known at the time of the accident as the 'Danwon High School survivors.' The group consisted of only 75 students, as 250 Danwon High School students were missing or dead.

Individuals in post-disaster settings may experience disaster-related psychiatric disorders, exacerbation of pre-existing psychopathological conditions, and/or psychological distress. ${ }^{1}$ A high proportion of New York City public school children had probable mental disorders, including agoraphobia (14.8\%), separation anxiety (12.3\%), and posttraumatic stress disorder (10.6\%), 6 months after September 11, 2001. ${ }^{2}$ Compared with untraumatized individuals, higher psychopathological symptom scores and suicide rates have been observed in adolescent survivors of earthquakes even 6 years after the event, and long-term psychological support may be required. ${ }^{3}$

A study using Twitter data to explore how the public mood in Korea changed following the Sewol ferry disaster demon- 
strated that the disaster generated a significant short-term negative response, which gradually declined. However, public anger was easily provoked by various events that occurred in the aftermath of the tragedy. ${ }^{4}$ This underlined the importance of monitoring mood changes in the general population following a disaster.

However, very little is known about the long-term mental health of the Danwon High School students who survived the Sewol ferry disaster. Analysis of follow-up data obtained from these individuals to understand how relevant psychological variables changed is important for the development of more accurate predictions of the mental health outcomes of adolescents who survive tragedies. The students who survived the Sewol ferry disaster experienced not only life-threatening trauma but also loss of close friends. Additionally, failures in the national disaster response process left them feeling let down and resentful, and the intrusive broadcasting that followed the tragedy increased their antipathy and mistrust. Moreover, distorted news reports led to cyberbullying and malicious comments, which left the students feeling hurt and confused. 5

The aim of this study was to examine relevant changes in psychological parameters, including anxiety, depression, posttraumatic stress symptoms (PTSS), and complicated grief. To this end, we performed retrospective chart and prospective follow-up reviews of the Danwon High School survivors from 9 months after the disaster until the first summer vacation after they graduated from high school, which was 27 months after the tragedy.

\section{METHODS}

\section{Subjects and procedure}

The study data were obtained from students evaluated at the Danwon High School Mental Health Center in 2015 and a prospective cohort follow-up study 27 months after the Sewol ferry disaster. Danwon High School established the Mental Health Center after the tragedy, and a school doctor and psychologists provided the students at the high school with regular mental health checkups and any counselling required.

The subjects in this study were all second-grade students who had been on the ferry and survived the tragedy. Our research group included the school doctor and the psychologists at the Mental Health Center who distributed questionnaires to the 75 students to assess their mental health at different time points (T). The assessments were performed 9 months (T1), 12 months (T2), and 15 months (T3) after the disaster.

After graduation, students who had enrolled in the disaster cohort study and were now at university were invited to complete a further assessment during their first summer vacation, which was 27 months after the tragedy (T4). The doctor who had been at Danwon High School met with the subjects and gathered the data.

\section{Assessments}

Subjects completed the 'State' section of the State-Trait Anxiety Inventory for Children (STAIC-State), the Center for Epidemiological Studies-Depression (CES-D) assessment, the Child Report of Post-traumatic Symptoms (CROPS), and the Inventory of Complicated Grief (ICG).

The STAIC-State tool consists of 20 self-assessment questions and measures anxiety levels on a three-point scale, which includes the responses 'yes,' 'no', and 'intermediate.' Total scores range from 20 to 60, with higher scores indicating higher levels of anxiety. ${ }^{6}$ The Korean version of the STAIC assessment was standardized by Cho and Choi, ${ }^{7}$ who defined a total score of 49 as the cutoff value for severe symptoms of anxiety.

The CES-D assessment is a non-diagnostic screening measure of depression consisting of 20 items rated or a four-point scale. Scores of at least 21 are epidemiologically equivalent to depression. ${ }^{8}$ The Korean version of the CES-D was used in this study. ${ }^{9}$

The CROPS is a screening tool for PTSS in children who may have experienced a traumatic event. ${ }^{10}$ It comprises 26 items that assess PTSS over the previous 7 days. All items are rated using a three-point Likert scale (i.e., $0=$ 'none', $1=$ 'some,'

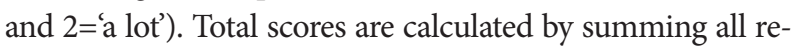
sponses, with higher scores indicating more severe PTSS. The cutoff that constitutes the level of clinical concern is currently defined as a score of 18. The CROPS was translated into Korean by Lee et al., ${ }^{11}$ who also confirmed its reliability and validity.

The ICG is a self-report measurement of the severity of CG symptoms. ${ }^{12}$ Each of its 19 items is rated on a five-point Likert scale from 0 (not at all) to 4 (severe). The internal consistency of the ICG is high (Cronbach's $\alpha=0.94$ ), and its concurrent validity relative to the Beck Depression Inventory is acceptable $(\mathrm{r}=0.67, \mathrm{p}<0.001) .{ }^{13} \mathrm{~A}$ score of 25 is regarded as the cutoff for whether a bereaved subject has CG symptoms.

\section{Ethical statement}

This study was approved by the Institutional Review Board for Human Subjects at the National Medical Center in Korea (IRB No. H-1505-054-002). Written informed consent was obtained from all participants. All participants were informed that they could withdraw from the study at any time.

\section{Statistical analysis}

Initially, we generated descriptive statistics to examine the 
means and standard deviations of the psychological variables and calculated the percentage of subjects in each group with clinically relevant symptoms. Changes in the STAIC-State, CES-D, CROPS, and ICG assessment scores were analyzed using one-way repeated-measures analysis of variance (ANOVA). The Statistical Package for the Social Science (SPSS) for Windows software (ver. 18.0; SPSS Inc., Chicago, IL, USA) was used for all statistical analyses, and the threshold for twosided significance tests was $\mathrm{p}<0.05$.

\section{RESULTS}

The retrospective chart review yielded complete responses from 68, 66, and 40 students at T1, T2, and T3, respectively (Table 1). The prospective follow-up review at T4 yielded data from 44 students (Table 1). Only data from the 32 subjects who

Table 1. Times of assessments and receipt of completed responses from Danwon High School survivors

\begin{tabular}{llcc}
\hline & \multicolumn{1}{c}{ Time } & $\begin{array}{c}\text { Subjects } \\
\text { (response rate, \%) }\end{array}$ & $\begin{array}{c}\text { Male/ } \\
\text { female }\end{array}$ \\
\hline T1 (9 months) & January, 2015 & $68(90.7)$ & $31 / 37$ \\
T2 (12 months) & April, 2015 & $66(88.0)$ & $31 / 35$ \\
T3 (15 months) & July, 2015 & $40(53.3)$ & $24 / 16$ \\
T4 (27 months) & July, 2016 & $44(58.7)$ & $23 / 21$ \\
\hline
\end{tabular}

T1: time point 1, T2: time point 2, T3: time point 3, T4: time point 4, months: months after the Sewol ferry disaster completed all four assessments were analyzed to examine changes in the relevant psychological variables.

Changes in the number of subjects with clinically relevant symptoms over time are shown in Table 2. STAIC-State scores indicated that $15.6-37.5 \%$ of subjects had clinically relevant symptoms and that the scores peaked at T2. Additionally, $18.8-34.3 \%$ of subjects had clinically relevant symptoms according to their CES-D scores. In terms of the CROPS assessment, $21.9-31.3 \%$ of subjects had scores that above the cutoff point. The ICG indicated that $12.5-28.1 \%$ of subjects had clinically relevant symptoms and that the scores peaked at T2.

All the psychological variables followed similar trends during the study period (Figure 1). Scores tended to increase until T2 (12 months) and then slowly decreased until the followup assessment at T4 (27 months). Analyses using one-way repeated-measures ANOVA revealed that the severity of anxiety and complicated grief symptoms, measured using the STAIC-State and ICG assessment tools, changed significantly over time. However, the severity of depression and PTSS, measured using the CES-D and CROPS assessment tools, did not change significantly during the study period. The mean STAIC-State score increased from $35.43 \pm 6.9$ at $\mathrm{T} 1$ to $37.81 \pm 7.3$ at $\mathrm{T} 2$; it then decreased to $33.31 \pm 7.8$ at $\mathrm{T} 4[\mathrm{~F}(3,93)=5.35, \mathrm{p}<0.01]$. The mean ICG score increased from $15.87 \pm 11.9$ at $\mathrm{T} 1$ to $17.93 \pm 13.0$ at $\mathrm{T} 2$; it then decreased to $11.12 \pm 10.0$ at $\mathrm{T} 4[\mathrm{~F}(3$, $93)=4.91, \mathrm{p}<0.01]$.

Table 2. Clinical groups according to the STAIC-State, CES-D, CROPS, and ICG assessments by time of assessment

\begin{tabular}{lcccc}
\hline \multicolumn{1}{c}{ Measure (N=32) } & T1 (9 months), $\mathrm{N}(\%)^{*}$ & T2 (12 months), N (\%)* & T3 (15 months), N (\%)* & T4 (27 months), N (\%)* \\
\hline STAIC-State & $8(25.0)$ & $12(37.5)$ & $8(25.0)$ & $5(15.6)$ \\
CES-D & $10(31.3)$ & $11(34.4)$ & $10(31.3)$ & $6(18.8)$ \\
CROPS & $10(31.3)$ & $9(28.1)$ & $7(21.9)$ & $8(25.0)$ \\
ICG & $7(21.9)$ & $9(28.1)$ & $7(21.9)$ & $4(12.5)$ \\
\hline
\end{tabular}

*the number of subjects with clinically relevant symptoms. STAIC-State: State Anxiety Scale of the State-Trait Anxiety Inventory for Children, CES-D: the Center for Epidemiologic Studies-Depression Scale, CROPS: Child Report of Post-traumatic Symptoms, ICG: the Inventory of Complicated Grief, T1: time point 1, T2: time point 2, T3: time point 3, T4: time point 4, months: months after the Sewol ferry disaster

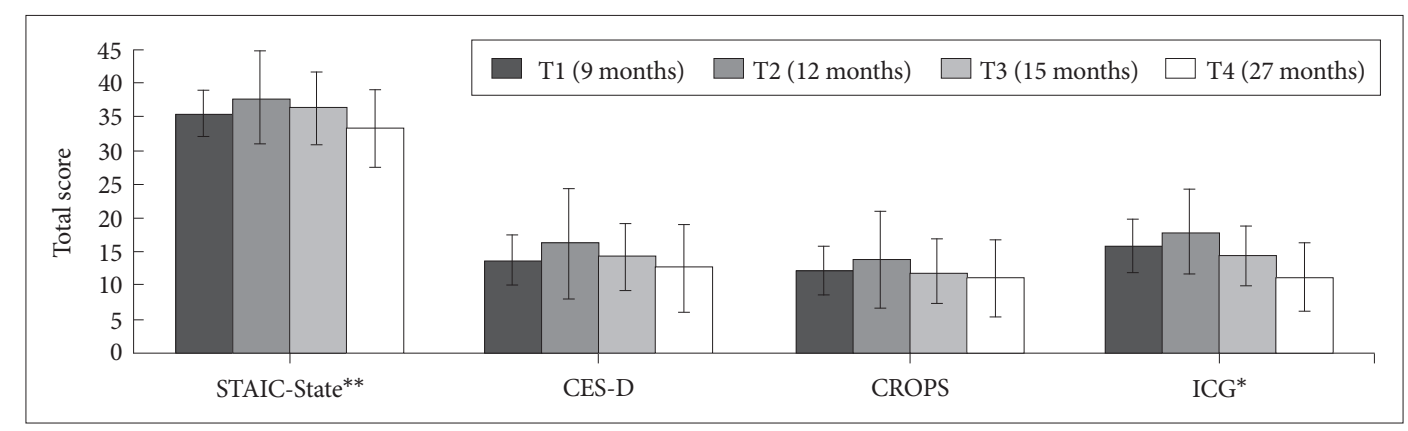

Figure 1. Changes in symptom severity over time according to STAIC-State, CES-D, CROPS, and ICG scores. ${ }^{*} p<0.05$, ${ }^{* *} p<0.01$. STAICState: State Anxiety Scale of the State-Trait Anxiety Inventory for Children, CES-D: the Center for Epidemiologic Studies-Depression Scale, CROPS: Child Report of Post-traumatic Symptoms, ICG: the Inventory of Complicated Grief, T1: time point 1 (9 months after the ferry disaster), T2: time point 2 (12 months after the ferry disaster), T3: time point (18 months after the ferry disaster), T4: time point 4 ( 27 months after the ferry disaster). 


\section{DISCUSSION}

We described changes in the psychological profiles of a sample of students who survived the Sewol ferry disaster. The Danwon High School survivors showed aggravated symptoms of anxiety and complicated grief at the first anniversary of the tragedy but significant improvements in these symptoms 27 months after the disaster, following their graduation from high school. However, their symptoms of depression and PTSS did not change significantly throughout the study period.

Several empirical and longitudinal studies have reported that an anniversary of a traumatic event can trigger an increase in distressing memories of this event. Morgan et al. ${ }^{14}$ examined anniversary responses to Operation Desert Storm and Operation Desert Shield in veterans 2 and 6 years after the end of each conflict. When the veterans' worst months were compared with the dates of the traumatic events that occurred during the Operations, we found that $38 \%$ of veterans had reported that their worst month coincided with the month in which their trauma had actually occurred. Our study noted that Danwon High School erected a makeshift memorial wall of flowers with photographs of the dead and missing students on the anniversary of the disaster. Many of the surviving students spent considerable time at the memorial, and this could have had an effect on their response to the anniversary of the tragedy. ${ }^{15}$

Our findings are broadly consistent with those of previous long-term follow-up studies of children who witnessed a fatal incident at school. As time passed, mean anxiety symptom scores decreased, but symptoms of depression remained largely unchanged. ${ }^{16}$ In our study, the school itself might have triggered traumatic memories, and graduation might have reduced students' symptoms of anxiety and complicated grief. The surviving Danwon students also had to cope with distorted news reports, malicious comments, and cyberbullying, some of which resulted from the government's decision to give them special status for admission to college on the assumption that they were unable to study following the deaths of nearly 300 of their schoolmates. The students might have felt freed of this stigmatization after they graduated from school and went to university or became integrated into society.

In contrast, we found that the severity of PTSS remained relatively unchanged throughout the study period. This differs from the results of many studies that found a general decline in the prevalence of post-traumatic stress disorder (PTSD) over time. For example, data from survivors of the 1991 mass shooting in Killeen, Texas suggest that the prevalence of PTSD decreased from $27.2 \%$ at 6-8 weeks to $17.7 \%$ at $13-14$ months after the episode. ${ }^{17}$ The prevalence of PTSD in tsunami victims was $57.3 \%$ at 6 weeks, but it declined sharply 2 years after the event. ${ }^{18}$ Other studies reported increases in PTSD prevalence over time. For example, the prevalence of PTSD in a cohort of Dade County, Florida residents exposed to Hurricane Andrew in 1992 increased from 26\% to 29\% between 6 and 30 months following the disaster. Clearly, the course of PTSD needs to be assessed over a significant period of time to accurately assess the prognoses of survivors of traumatic events. ${ }^{19}$

In our study, the prevalence of PTSD was $25.0 \%$ at 27 months after the disaster. The development of PTSD in juveniles following a tragedy can vary significantly, and its prevalence can range from $0 \%$ to $95 \%$. The prevalence of PTSD observed in this study was comparable to that following man-made disasters $(20.3-29 \%)^{20}$ and higher than that reported in studies on flood survivors (15.74\%). ${ }^{21}$ A number of factors could account for differences in the observed prevalence of PTSD in different studies. These include differences in the type of trauma, the degree of exposure to the trauma, the characteristics of the traumatized population, the specific measurements used to define PTSD, and the time between the traumatic event and the assessment of PTSD and anxiety.

This 27-month follow-up study found that the prevalence of depression among subjects was $18.8 \%$. This is higher than the prevalence of depression in an indirectly affected sample from Ansan, where most of the students on the ferry had lived. ${ }^{22}$ However, this indirectly affected population had a higher prevalence of psychiatric problems compared with control communities. The rates of depression, moderate-to-severe stress, somatic symptoms, anxiety, and suicidal ideation in the Ansan population sample were 11.4, 8.8, 11.9, 5.9, and $17.7 \%$, respectively.

This study had several limitations. First, some sampling bias may have occurred. Although $59-91 \%$ of the sample population participated in the study between $\mathrm{T} 1$ and $\mathrm{T} 4$, only $43 \%$ of the surviving students completed all four assessments and provided data that were used in the statistical analyses. Therefore, the results should be interpreted with caution. Second, the prevalence of PTSD was measured using a self-report assessment tool rather than a structured clinical interview. Selfreporting does not always provide an accurate representation of PTSD symptomatology. However, the CROPS assessment tool used in this study was well validated for Korean children and adolescents. Finally, we did not include comparison groups and could not compare the study subjects with a control group.

In conclusion, despite these limitations, our study provides significant insight, as we demonstrated that the Danwon High School survivors clearly responded to the first anniversary of the Sewol ferry disaster. Additionally, we examined longitudinal changes in key psychological variables and found that the severity of anxiety and complicated grief symptoms de- 
creased significantly but that symptoms of depression and PTSS persisted even after graduation from high school. These results have unique implications in terms of the need for regular screening to improve the mental health of disaster survivors. They also underscore the importance of providing longterm follow-up services for mental health problems in general and for PTSD in particular. A combination of quantitative and qualitative data could provide further insight into why some psychological variables changed more than others in survivors of the Sewol ferry disaster.

\section{Acknowledgements}

This study was supported by a grant from the Korean Mental Health Technology R\&D Project, Ministry of Health \& Welfare, Republic of Korea (HM15C1054).

\section{REFERENCES}

1. North CS, Pfefferbaum B. Mental health response to community disasters: a systematic review. JAMA 2013;310:507-518.

2. Hoven CW, Duarte CS, Lucas CP, Wu P, Mandell DJ, Goodwin RD, et al. Psychopathology among New York city public school children 6 months after September 11. Arch Gen Psychiatry 2005;62:545-552.

3. Tanaka E, Tsutsumi A, Kawakami N, Kameoka S, Kato H, You Y. Longterm psychological consequences among adolescent survivors of the Wenchuan earthquake in China: a cross-sectional survey six years after the disaster. J Affect Disord 2016;204:255-261.

4. Woo H, Cho Y, Shim E, Lee K, Song G. Public trauma after the Sewol Ferry disaster: the role of social media in understanding the public mood. Int J Environ Res Public Health 2015;12:10974-10983.

5. Kim SS. Results of the studies on supports for the victims of the Sewol Ferry disaster. Presentation on the results of the studies on supports for the victims of the Sewol Ferry disaster. Seoul: Kim Koo Museum \& Library; July 20, 2016.

6. Spielberger CD. Manual for State-Trait Anxiety Inventory for Children. Palo Alto, CA: Consulting Psychologists Press; 1973.

7. Cho SC, Choi JS. Development of the Korean form of the State-Trait. Anxiety Inventory for children. Seoul J Psychiatry 1989;14:150-157.

8. Radloff LS. The CES-D scale: a self report depression scale for research in the general population. Appl Psychol Meas 1977;1:385-401.

9. Cho MJ, Kim KH. Diagnostic validity of the CES-D (Korean version) in the assessment of DSM-III-R major depression. J Korean Neuropsychiatr Assoc 1993;32:381-399.

10. Greenwald R, Rubin A. Assessment of posttraumatic symptoms in children: development and preliminary validation of parent and child scales. Res Soc Work Pract 1999;9:61-75.

11. Lee KM, Jeong SH, Lee WK, Chung US. Reliability and validity of the Korean version of the Child Report of Post-Traumatic Symptoms (CROPS) and the Parent Report of Post-Traumatic Symptoms (PROPS). J Korean Acad Child Adolesc Psychiatry 2011;22:169-181.

12. Shear K, Frank E, Houck PR, Reynolds CF 3rd. Treatment of complicated grief: a randomized controlled trial. JAMA 2005;293:2601-2608.

13. Prigerson HG, Maciejewski PK, Reynolds CF 3rd, Bierhals AJ, Newsom JT, Fasiczka A, et al. Inventory of complicated grief: a scale to measure maladaptive symptoms of loss. Psychiatry Res 1995;59:65-79.

14. Morgan CA, Hill S, Fox P, Kingham P, Southwick S. Anniversary reactions in Gulf War Veterans: a follow-up inquiry 6 years after war. Am J Psychiatry 1999;156:1075-1079.

15. Memories and traces of students lost in South Korean ferry disaster. Available at: http://edition.cnn.com/2014/04/25/world/asia/south-korea-lost-students/. Accessed May 13, 2017.

16. Song SH, Kim BN, Choi NH, Ryu J, McDermott B, Cobham V, et al. A 30-month prospective follow-up study of psychological symptoms, psychiatric diagnoses, and their effects on quality of life in children witnessing a single incident of death at school. J Clin Psychiatry 2012;73: e594-e600.

17. North CS, Smith EM, Spitznagel EL. One-year follow-up of survivors of a mass shooting. Am J Psychiatry 1997;154:1696-1702.

18. Piyasil V, Ketumarn P, Prubrukarn R, Ularntinon S, Sitdhiraksa N, Pithayaratsathien $\mathrm{N}$, et al. Post-traumatic stress disorder in children after the tsunami disaster in Thailand: a 5-year follow-up. J Med Assoc Thai 2011;94(Suppl 3):S138-S144.

19. Norris FH, Perilla JL, Riad JK, Kaniasty K, Lavizzo EA. Stability and change in stress, resources, and psychological distress following natural disaster: findings from Hurricane Andrew. Anxiety Stress Coping 1999;12:363-396.

20. Neria Y, Nandi A, Galea S. Post-traumatic stress disorder following disasters: a systematic review. Psychol Med 2008;38:467-480.

21. Chen L, Liu A. The incidence of posttraumatic stress disorder after floods: a meta-analysis. Disaster Med Public Health Prep 2015;9:329333.

22. Yang HJ, Cheong HK, Choi BY, Shin MH, Yim HW, Kim DH, et al. Community mental health status six months after the Sewol Ferry disaster in Ansan, Korea. Epidemiol Health 2015;37:e2015046. 